\title{
La cuentística erótica de Jaramillo Levi a través desus máquinas deseantes ${ }^{1}$
}

\section{Fátima R. Nogueira ${ }^{2}$}

The University of Memphis, Estados Unidos

$\mathbf{r}_{\text {esumen }}$

Se estudia la narrativa de Jaramillo Levi centrada en la relación entre el erotismo y la muerte, desde el intercambio de dos fuerzas que actúan en la producción del deseo: una, de naturaleza libidinosa e inconsciente, la otra de filiación social. Estos relatos exploran el vínculo entre las pulsiones sexuales y el instinto de la muerte revelando el exceso y la violencia ocultos en el erotismo; además, plasman la magnitud del deseo que al exceder los límites del cuerpo y del individuo deviene una experiencia de la sexualidad inhumana reafirmada sólo por un campo saturado de intensidades y vibraciones. Partiendo de la teoría lacaniana del deseo, y de conceptos de Deleuze y Guattari, en los relatos tal encuentro de fuerzas objetiviza el sujeto y cuestiona la noción antropomórfica de sexualidad.

\footnotetext{
abstract

This study deals with Jaramillo Levi's short stories centered on the relationship between eroticism and death, examining the exchange of two driving forces which create desire. The nature of one of these forces is unconscious and libidinous while the other is social. These stories explore the link between sexual drive and the death instinct, disclosing overindulgence and violence hidden behind eroticism. In addition, they depict the magnitude of desire, which upon exceeding the boundaries of the human body and the individual, becomes an experience of inhuman sexuality that can reaffirm itself only in a field permeated with intensity and vibrations. Considering Lacan's theory of desire and other concepts from Deleuze and Guattari, the exchange of forces in these stories objectifies the subject and questions the anthropomorphic notion of sexuality.

1 Ponencia presentada en el XX Congreso Internacional de Literatura Centroamericana (ciLca) 2012. Recibido: 30 de marzo de 2011; aceptado: 12 de junio de 2011.

2 Correo electrónico: nogueira @ memphis.edu
}

$$
L_{\text {etras }} 49 \text { (2011), ISSN 1409-424X }
$$


Palabras clave: narrativa centroamericana, literatura panameña, erotismo y sexualidad, literatura y psicoanálisis

Keywords: Central American narrative, Panamanian literature, eroticism and sexuality, literature and psychoanalysis

En el prólogo de Duplicaciones (1973), Jaramillo Levi observa que varios de sus cuentos abordan el «tema general de la duplicidad de ciertas situaciones humanas ligadas al erotismo y a la muerte» $(9)^{3}$. Esta alusión sitúa tal temática entre las que se han constituido como vertientes reiteradas en la obra del escritor panameño, en la cual Duplicaciones constituye el marco inicial de recepción y fortuna crítica. Es decir, conjuntamente con otros temas y motivos, se destaca una especie de fascinación con lo erótico y la sexualidad en la cual se vinculan tanto al desarrollo síquico del individuo como a las formaciones sociales a las cuales él se integra. Esta doble vinculación propone que el deseo no sólo es fruto de fuerzas síquicas $\mathrm{y}$, por tanto, individuales sino que se conforma también como una producción social.

Vamos a centrarnos aquí en la relación entre Eros y la muerte a partir de que el tópico de la sexualidad adquiere en la cuentística de Jaramillo Levi. Selecciono algunos relatos que tratan el tema desde variadas perspectivas en el desarrollo de la narrativa del autor: $« \mathrm{El}$ búho que dejó de latir» y «El ofertorio» de Duplicaciones, «El temblor» $\mathrm{y}$ «No te rías de mí», recompilados en Romper el molde $(2005)^{4}$ y «La octava noche», de En un instante y otras eternidades (2005) En el análisis de estos cuentos la relación entre el erotismo y la muerte se establece en dos direcciones principales. La primera, de naturaleza sicoanalítica remite a la ligación de la sexualidad a la pulsión de la muerte, convocando el erotismo en su exceso y revelando su violencia La segunda, refiere a una sexualidad que sobrepasa lo meramente humano, concediendo importancia a la magnitud del deseo y

3 Enrique Jaramillo Levi, Duplicaciones, $3^{\text {a }}$ ed. (Madrid: Editorial Orígenes, 1990).

4 Enrique Jaramillo Levi, Romper el molde: 29 cuentos eróticos (San José: URUK Editores, 2005).

5 Enrique Jaramillo Levi, En un instante y otras eternidades (Panamá: Editorial Mariano Arosemena, 2006). 
aproximándolo en ciertas ocasiones a una naturaleza en estado caótico. Esta sexualidad inhumana se presenta como consecuencia de una visión del deseo como producción conectada a diversos campos. En este sentido, se destaca una dimensión del deseo que abarca — como propusieron Deleuze y Guattari- todo su entorno, es decir, no sólo cuerpos y objetos sino que también flujos y vibraciones $(292)^{6}$. Asimismo esta sexualidad inhumana, que se opone a la representación antropomórfica de la sexualidad, corresponde a la noción de maquinas deseantes en la teoría propuesta por estos pensadores (296).

«El búho que dejó de latir» trata de la recomposición de la vida de un individuo, víctima de un crimen pasional, a través de sus recuerdos en los momentos que anteceden su muerte. El enfoque en la pulsión de muerte se construye desde algunas imágenes perturbadoras que conllevan tanto al instinto de la muerte en su acepción sicoanalítica como a la noción de Deleuze y Guattari de máquinas deseantes. Corrobora a la orientación del relato hacia el instinto de la muerte la escena que cierra el cuento con su perturbadora imagen de los cuerpos copulando después de decretada su muerte clínica. Se recobra en la referida escena una concepción freudiana en la cual la repetición y la pulsión de muerte se vinculan: «La meta de la vida es la muerte; y, retrospectivamente: lo inanimado que estuvo ahí antes de lo vivo» (38) ${ }^{7}$. La repetición conlleva el movimiento del autómata así como las evoluciones de la penetración sexual. Sin embargo, esta misma escena debido a la intromisión de la alegoría —un hombre con cabeza de búho, una mujer sin cabeza y otra, con cara de hiena- repite de cierta forma otras escenas de desmembramiento de órganos que trataremos a continuación. Estas fragmentaciones del cuerpo humano interesan en la medida que deshacen la duplicidad de las pulsiones de la concepción freudiana, aproximándose

6 Gilles Deleuze y Félix Guattari, Anti-Oedipus. Capitalism and Schizophrenia (Minneapolis: University of Minnesota Press, 2005). Todas las referencias subsiguientes a los conceptos de máquinas deseantes y cuerpo sin órgano pertenecen a la misma obra.

7 Sigmund Freud, Más allá del principio de placer. Obras completas, XVIII. 2. a ed. (Buenos Aires: Amorrortu Editores, 2007). 
a la concepción de máquinas deseantes, no sin antes cruzar la teoría del deseo lacaniana ya que el sicoanalista francés había declinado la existencia de dos pulsiones diferenciadas al desarrollar la dialéctica de la jouissance asociada a la repetición así como a la pulsión de muerte. En esta dirección Homer postula que «Para Lacan toda pulsión es de naturaleza sexual y al mismo tiempo es una pulsión de muerte» $(76)^{8}$.

Deleuze y Guattari rechazan la concepción de un instinto de muerte en oposición simétrica a la pulsión de vida, postulando que estas dos pulsiones son dos diferentes partes de una misma máquinadeseante (329). Según ello, el cuerpo sin órganos es el modelo de la muerte que alcanza la intensidad cero. Un concepto complejo que apunta a la reinserción de la improductividad en el proceso de producción, representando un tercer estadio de producción en el cual se configura como un objeto enorme e indiferenciado en el momento en que todo se congela en un punto fijo para recomenzar nuevamente. En este sentido representa el éxtasis absoluto revelado en el momento en que el autómata cesa de producir: «Todo el cuerpo sin órganos es lo improductivo, lo estéril, lo que no se engendra, lo que no se pude consumar» (8). Es decir que mientras la máquina social atrae los flujos del capital, el cuerpo sin órganos cuenta con sus propias inversiones del deseo, su esencial carencia utilitaria.

Se vislumbra la plasmación estética del modelo de la muerte en «El búho que dejó de latir» en una escena cuyas imágenes se centran en el desmembramientos de órganos del cuerpo humano - recordando los procedimientos de la vanguardia literaria al promover una conjunción entre el discurso del delirio y la imagen- que rehúsan configurarse nuevamente en una totalidad que pueda asemejarse a un organismo:

8 Sean Homer, Jacques Lacan (Londres: Routledge, 2005). 
Una nariz camina por un parque. $\mathrm{Al}$ poco rato se encuentra con una boca. [...]Casi en seguida son interceptados por un par de orejas. [...] Al llegar junto a una banca la nariz percibe un leve olor a sal. La boca separa sus labios y saca la lengua a tiempo para atrapar una lágrima que caía del ojo que yace sobre la banca [...] Se acerca un hombre. Saca otro ojo del bolsillo [...] El hombre saca papel y lápiz, dibuja los bordes de una cara, coloca el papel sobre la banca y arregla los dos ojos, la nariz, las dos orejas y la boca sobre la cara [...] Del bolsillo del pantalón extrae entonces un pequeño espejo [...] cuando los ojos se ven en el espejo, saltan de sus órbitas y corren aterrorizados... (215-16).

Aunque la plasmación estética alude a órganos desmembrados del cuerpo humano se podría hablar del modelo de la muerte a partir de la configuración del cuerpo sin órganos precisamente por el claro rechazo a una armonía que presuponga una unidad. Es decir que la plasmación del referido cuerpo se basa en la fragmentación y en la adjunción de todo el entorno a estos miembros. Se observa también en este episodio que la realización estética del modelo de la muerte anuncia la muerte como experiencia, pues el rechazo de los órganos a volver a integrarse al cuerpo simboliza de cierta forma la expiración inminente del protagonista del relato. Este cuerpo sin órganos como figura de lo que se derrocha rehuyendo la constitución de una entidad puesto que ésta sería institucionalizada e invertida como potencial ganancia social, deviene en el texto aquí discutido el punto modal de alteridades a través del cual las experiencias humanas no pueden hacerse divisibles. Más específicamente, la metáfora de «El búho que dejó de latir» relativa a una representación del modelo de la muerte converge en la del cuerpo sin órganos. La misma fragmentación se repite en un irónico diálogo entre los órganos sexuales:

«A ella no le importa en realidad, después que le dé lo que quiere, cuando lo quiere», comenta un pene rosado de aspecto cansado. «Pero llegará el momento en que estarás demasiado agotado para contentarla», 
exclama simultáneamente un par de senos. «Si yo te puedo compartir, también debería hacerlo ella, abiertamente, y dejarse de formalidades y legalismos tontos», balbucea la vagina irritada (220).

La función estructural de este diálogo se desdobla en un reflejo de la anécdota del cuento y en una crítica a la sociedad y sus instituciones respecto a una distribución de los placeres y de los poderes del sexo, que Foucault ha analizado en The History of Sexuality (3649) a partir de la constatación de que las ciencias médicas - incluyendo el sicoanálisis - y los modelos educativos unidos a otros sistemas sociales, construyeron algunos dispositivos de saturación del sexo para mantener el control sobre la sexualidad ${ }^{9}$. En el caso de $« \mathrm{El}$ búho» se percibe en la configuración del crimen pasional que tiene lugar al final del cuento una crítica a las instituciones sociales que organizan privilegiadamente la sexualidad y la distribución de los placeres alrededor de la pareja monogámica y heterosexual. Por otra parte, en esta visión crítica manifiesta un aspecto social del deseo, añadiendo a la referida distribución la función sexual que esta pareja tiene que cumplir obligatoriamente.

«El ofertorio» $\mathrm{y}$ «El temblor» establecen una relación directa entre el sexo y una naturaleza caótica que anuncia un desastre inminente, lo que nos sitúa ante la perturbadora posibilidad de pensar la sexualidad en su aspecto inhumano. La doble dirección establecida en estos relatos permite, por un lado, establecer relaciones con ciertas pulsiones de los estados inconscientes y, por otro, cuestionar las maneras por las cuales se produce el deseo y las fantasías individuales, aproximándolos de ciertas construcciones de la realidad social. Es decir que se establece simultáneamente relaciones a conceptos psicoanalíticos y a construcciones sociales en la medida que los personajes de estos cuentos esperan a la muerte mientras copulan a la vez que revisten la relación sexual de un significado ritual,

9 Michael Foucault, The History of Sexuality Vol. I: An Introduction (Nueva York: Pantheon Books, 1978). 
incorporándole fantasías y deseos colectivos. Jaramillo Levi acopla, así, de manera directa la relación sexual al estado de regreso a una especie de nirvana. En el primero de estos textos, los espasmos provocados por el orgasmo coinciden con los de la tierra en tanto que en «El ofertorio» se convoca ritualmente una ofrenda de cuerpos en copulación mientras se espera un desastre amenazador. Es necesario recalcar que este estado de alteridad que vincula sexo y muerte a través de la fase orgásmica no se lleva a cabo sin la participación plena de compulsiones automatizadas en que lo repetitivo no es verdaderamente una condición que conduzca a un resultado sino un alto efecto de visualización recogido en el propio placer y cuya inconclusión reanima el disfrute hasta su ingreso en la fase de un estado de alteridad delirante.

En relación con el psicoanálisis, la inserción de la naturaleza caótica mediando entre el sexo y la muerte parece relacionarse con un conocimiento primigenio cuyo recorrido produce un efecto entrópico. Las repercusiones de este saber originario fueron introducidas por Lacan en la discusión de la naturaleza dialógica de la jouissance y desarrollado en The Other Side of Psychoanalysis (45-51) ${ }^{10}$. Valga decir que este tipo de saber revela la presencia de una relación entre el ser humano y la naturaleza, enmarcada por la pulsión de la muerte en lo que concierne al movimiento retroactivo hacia lo inanimado. Así, la coincidencia entre las convulsiones del orgasmo y los espasmos de la tierra en «El temblor» así como la ofrenda de cuerpos en copulación en «El ofertorio» — mientras se espera por la catástrofe que se anuncia - no sólo cancelan la oposición entre el ser humano y la naturaleza sino que también restituyen una relación primitiva entre la naturaleza y el conocimiento. No se trata aquí, sin embargo, de un saber institucionalizado y ordenador, relacionado a la ciencia, sino más bien de un conocimiento ancestral que repite los pasos previamente trazados para retornar a lo inanimado y se 
opone radicalmente a las fuerzas que resisten a la muerte. Dicho de otra forma, existe un conocimiento ancestral que se organiza en la repetición para retornar a un estado original de fusión completa con la naturaleza, que sólo se puede alcanzar a través de la muerte. Ahora bien, al hablar de un conocimiento ancestral que conduce la pulsión de la muerte, Lacan y de cierta forma también Freud, abren un espacio que ayuda a esclarecer, aunque de forma insuficiente, la inserción directa de la naturaleza caótica en la vinculación de sexo y muerte, es decir, el hecho de que este tipo de conocimiento salga del ámbito de la subjetividad para configurarse en una característica compartida por la humanidad como especie.

Sin embargo, una más amplia comprensión del papel que desempeña la naturaleza en la ligación entre la sexualidad y la muerte —especialmente en los cuentos «El ofertorio» $\mathrm{y}$ «El temblor»exigiría traspasar la frontera de la representación antropomórfica de la sexualidad, es decir salir del ámbito del psicoanálisis para entrar en el campo del esquizoanálisis, que muy sintética y sencillamente podríamos definir como un tipo de análisis en que Deleuze y Guattari unen la producción social y la producción del deseo. Holland entiende el esquizoanálisis como una psiquiatría históricorevolucionaria-materialista-semiótica (241-242), y explica como el concepto de desterritorialización, una de las nociones claves de la teoría de Deleuze y Guattari, deriva del concepto lacaniano de territorialización que organiza el cuerpo humano en zonas erógenas y no erógenas afirmando que:

Para Deleuze Y Guattari la desterritorialización en el registro psicológico designa el proceso de liberar la libido de objetos de inversión preprogramados como el seno materno o el triángulo familiar del complejo de Edipo, de suerte que estas inversiones puedan ser realizadas en otra parte. En Deleuze y Guattari, aunque estos términos sean originariamente psicológicos, también operan en el registro social, donde designan una dinámica crucial del mercado 
capitalista: la desconexión y reconexión de cuerpos productivos y de ambientes $(242)^{11}$.

Del proceso de producción que interviene en la dilucidación del concepto de esquizoanálisis, el radio de la naturaleza inhumana de la sexualidad opera como herramienta esencial para esclarecer la funcionalidad de la naturaleza en la vinculación que Jaramillo Levi establece entre el sexo y la muerte. Deleuze y Guattari asocian este principio a la concepción lacaniana del Otro (295), resaltando que en el caso del esquizoanálisis esta noción se desvincula del complejo de Edipo y de la castración. Entender la naturaleza inhumana de la sexualidad exige apartar todo el mecanismo del deseo de la configuración de la persona individual así como requiere un entendimiento de la primacía del campo social en las energías liberadas por el deseo. De esta forma, como proponen Deleuze y Guattari, las inversiones - lo que cada ser humano prevé provechoso para sí mismo- y las formaciones del deseo son de naturaleza colectiva (280). Es evidente que en lo que concierne al sentimiento de alteridad que enlaza muerte y sexo en los textos de Jaramillo Levi discutidos, se observa una conjunción de diferentes campos que hace legítima su naturaleza social. Es decir que se trataría de mediaciones de naturaleza semántica que asocian el orgasmo a la muerte - como acontece en la lengua francesa - lo que permitiría a su vez la participación de un elemento de carácter biológico en la elaboración de esta alteridad. Por otra parte, la condición social de la producción del deseo, que constituye parte integrante de la naturaleza inhumana de la sexualidad, toma en cuenta la magnitud del deseo que, según postulan Deleuze y Guattari, arrastra consigo también «El entorno social así como el biológico son el objeto de la inversión inconsciente que es necesariamente deseante o libidinosa, en contraste con las inversiones preconscientes de necesidad o de interés» (292).

11 Eugene W. Holland, «Schizoanalysis and Baudelaire: Some Illustration of Decode at Work», Deleuze: A Critical Reader (Cambridge, MA: Blackwell Publishers, 1996) 240-56. 
En este sentido, se puede medir la intensidad de las vibraciones del acto sexual con las fuerzas cósmicas como demuestra Jaramillo Levi en «El ofertorio»: la pareja dejaba escapar ya sus últimos espasmos a sus pies cuando volvió a abrirlos [los ojos] el cielo era ahora una sólo nube negra, compacta» (Duplicaciones 88-89). También se puede extrapolar esta articulación entre las fuerzas cósmicas y la relación sexual, introduciendo aún más directamente la vinculación de la muerte al sexo como en este fragmento de «El temblor»: «El derrumbamiento se dejó venir súbito coincidiendo con el supremo goce. Nuestra deliciosa pequeña muerte y el inicio de esta otra tan agónica fueron un solo gran colapso» (Romper el molde, 28). Evidentemente, la noción de sexo inhumano no se equipara de ninguna manera en los cuentos aquí comentados con la presencia de las fuerzas cósmicas en la relación sexual. Al contrario, la sexualidad inhumana se relaciona a la noción de máquinas deseantes que tanto en «El ofertorio» como en «El temblor» incorporan las fuerzas cósmicas - transformadas en substancias que hacen fluir una energía libidinosa - a la relación sexual.

En «La octava noche» se asocia la naturaleza con la mujer, acentuando un proceso de devenir-abeja que orienta las fantasías sexuales de una ninfomaníaca, Violeta, que mantiene varios amantes en su casa para prepararlos para la gran orgia de la noche final y después eliminarlos. El erotismo de la protagonista se expande hacia una fijación en lo ritual: «La octava noche como en un ritual predispuesto, debíamos estar todos alrededor de la abeja reina, acosándola, alternando en su húmedo panal nuestros acechantes aguijones, haciéndola gritar de placer, antes de sucumbir nosotros» (En un instante y otras eternidades 45). Esta ritualización unida a un movimiento constante y repetitivo que se organiza alrededor de lo sexual — posiciones, parejas sucesivas, sexo colectivo - recuerda, incluso, a algunos personajes de Sade. De hecho la conformación del personaje mezcla el sadismo a algunas construcciones culturales respecto a lo femenino cuyo marco seria Afrodita quien anhela la liberación de la mujer y la brevedad de las relaciones amorosas. Evidentemente no es la potencial crueldad 
del personaje lo que acopla su sexualidad a lo inhumano sino dos rasgos sobresalientes en la distribución de la actividad sexual que ella comanda. El primero refiere a la dimensión desatada de su deseo que revela el lado desmesurado del placer, revelando lo que lo sobrepasa. Este hecho crea un espacio textual en que la violencia, lo irracional y lo desmesurado convocan el erotismo. Es decir que el cuento aquí comentado presenta una característica de la literatura erótica en general la cual consiste en transformar el texto en un doble del mundo espejando su violencia y su exceso. Es precisamente esta peculiaridad que se abre al siguiente rasgo sobresaliente del relato que se resume en estructurar el deseo como producción social.

Deleuze asocia el sadismo y el masoquismo a la desexualización y resexualización de Tánatos (114-15), que al liberar la violencia aproxima el sexo al instinto de la muerte ${ }^{12}$. La literatura erótica de Jaramillo Levi se inscribe en un deleite de la anormalidad y del exceso del deseo haciéndolos coincidir en una especie de condensación que abarca tanto la exaltación al derroche como una conjunción entre sexo y violencia. El goce generado por la explotación de estados patológicos hasta sus últimas consecuencias, como acontece en el caso del sadismo de la protagonista de «La octava noche», conlleva una aproximación entre un arte erótico - inscrito como síntoma- y la locura. Relacionándose a los cuentos que unen el sexo y la violencia a las enfermedades mentales, «No te rías de mí» compilado en Romper el molde se presenta como uno de los textos de más compleja realización estética en la obra de Jaramillo Levi. El cuento trata de un demente que adopta diversos estados tales como la esquizofrenia, el voyeurismo, la negación de su propia sexualidad y el travestismo. Al observar a su vecina Raquel desnudarse por la ventana, el protagonista narrador desarrolla por ella un sentimiento obsesivo que culmina en la invasión de su cuarto cuando ella se ausenta por una noche. La mujer lo sorprende precisamente en el momento en que él intentaba sacarse 
las ropas femeninas que se venía probando con deleite. Al descubrir «un gigante flaco y amanerado luchando histéricamente por quitarse una de [sus] más atrevidas minifaldas, tapándose los senos inexistentes con manos pudorosas» (51), Raquel desata en una risa que provoca el recuerdo de las humillaciones vividas por el protagonista en su infancia y adolescencia, identificándose a su hermano a quien él había asesinado en una situación semejante. La escena trasmutada abruptamente a una repetición del pasado en la mente enfermiza del protagonista redunda en el estrangulamiento de la vecina.

Interesa explorar la manera por la cual Jaramillo Levi transcribe las transformaciones sicológicas de este personaje escindido desde una cadena de significantes que lo conforman como sujeto. De esta forma el cuento se estructura metonímicamente a partir de la referida cadena la cual asociada a la pulsión escópica —el placer de mirar, según Lacan (178) - revela el centro de gravedad del deseo de su personaje central $^{13}$. Dicho de otra forma, el punto nodal desencadenador de esta red de significantes se constituye como el proceso metonímico que formado a partir de órganos — senos, nalgas, ojos, espalda, lengua, boca, mejilla, cuello, vientre - acciona la cadena de significantes en la cual el sujeto participa como uno de sus efectos. Este encadenamiento de órganos se encuentra con lo sensual formando otra serie en la cual la voz, la mirada, la linterna se asocian a pulsiones. Un efecto paralelo al que constituye el sujeto se aglutina alrededor del vocablo gato, que irrumpe repentinamente en el texto, permitiendo una interpretación de la sexualidad del protagonista que retrocede hasta su infancia y adolescencia. Significativamente se produce un nuevo proceso metonímico en el cual la palabra gato se asocia a Raquel, componiendo su voz imaginada como «el maullido de un gato» (Romper el molde, 48); su lengua, como la de un gato supuestamente le «recorrería la espalda» (48); sus ojos lo «hacen evocar los gatos» (48) y despiertan el deseo de «besarte en los ojos como hacía con mis gatos» (49). A partir de esta composición del deseo, cuya base 
se inscribe como repercusión del lenguaje en el nivel del Otro, se crea la imagen de Raquel como si fuese un gato: «Si fuera una de ellos te enseñaría a lamerme las mejillas, el cuello, mi vientre después, como antes. Me dormiría oyendo tu ronroneo» (49).

La proliferación metonímica se relaciona a la configuración del cuerpo sin órganos que acopla a sí todo lo entorno, incluyendo: los órganos del sexo femenino, específicamente los senos; los órganos y movimientos animales así como objetos hasta su total paralización en el modelo de la muerte. Asimismo la imagen plasmada en el relato remite hacia algunas propuestas de Lacan respecto a la lógica del deseo en relación a la dimensión lingüística del Otro ya que «este Otro debe ser definido en el lugar del discurso» $(37)^{14}$. El sicoanalista francés reafirma esta lógica planteando que porque «no se encuentra en el indicativo el deseo es lo que siempre se inscribe como repercusión de la articulación del lenguaje en el nivel del Otro. Es siempre el deseo del Otro como si estuviéramos siempre preguntando al otro lo que él desea» (37-38). Siguiendo esta línea, Lacan define al neurótico como «el sujeto cuyo deseo es que el Otro le pregunte [combinando] las cosas alrededor del deseo del Otro. Se pretende entonces que el Otro está pidiendo algo. Victimas, por ejemplo» (38-39). Transponiendo estos conceptos lacanianos a «No te rías de mí» sería posible plantear que el desplazamiento entre la demanda y el deseo que ocurre en la neurosis explicase retroactivamente el crimen ocurrido en el relato en el nivel de una captación inconsciente.

De esta forma, la imagen se desplaza retroactivamente creando otros significantes frente a los cuales se representa un sujeto escindido, es decir un sujeto que se asume como un efecto del significante, y que al caer en esta cadena inicia un proceso alucinatorio en el cual los dobles se multiplican. Se configura así el centro del deseo que sobrepasa lo humano no porque se sugiera que el protagonista mantuviese relaciones sexuales con sus gatos sino que estos configuran el objeto

14 Jacques Lacan, My Teaching (Nueva York: Verso, 2008). Las referencias a la teoría lacaniana que proceden esta cita pertenecen al mismo texto. 
- en cuanto suplemento del deseo- o residuo que conforma esta especie de desajuste entre la realidad y la imagen que la sostiene. Imagen que representa, a su vez, la desmesura de un deseo que sobrepasa los limites del cuerpo incorporando en sí un entorno de sensaciones, flujos y vibraciones: «Si me llamaras el aire que transmitiría tu voz me llegaría impregnado de tus ansias. Oliendo a tu boca. Con sabor a tu saliva espesa acumulada antes de tomar la decisión» (48). Se ilustra también el exceso del deseo a través del travestismo del protagonista sugerido como fuente de proliferación de fetiches. En este sentido al probar las ropas de Raquel estas piezas asumen una doble función. Por un lado revelan el deleite de asumirse como doble de Raquel, por otro se constituyen como medio de la posesión de la misma: «me convierto en tu doble, te imito, logro habitarte. Eres mía, y así soy yo, femenina, como he querido ser siempre. Como debí haber nacido» (51). Todo el proceso de transformación y objetivación del sujeto al culminar en una combinación de voyerismo, travestismo y fetichismo exacerbado, insinúa que el personaje en sus procedimientos alucinatorios transforma todo lo que ve o toca en fetiche, involucrando el desvanecimiento del objeto de deseo. Es decir que éste se trasmuta en fetiche. De esta manera Raquel podría conformarse también como fetiche y la súbita ruptura con la fantasía, o mejor dicho, su aparición como figura real desencadena la violencia. Por otra parte al congelarse toda la jouissance en una profusión de fetiches se provoca una especie de objetivación traducida por toda una maquinaria que convoca el instinto de la muerte. Nos situamos aquí nuevamente frente a algunos conceptos de Deleuze y Guattari que tienen que ver con el cuerpo sin órganos y su doble actividad en tanto representación de las dos caras del deseo conformándose como el modelo de la muerte al repeler los órganos entendidos en su función de objetos parciales - y como una máquina fetichista al atraerlos (328-329).

El énfasis en los órganos del cuerpo humano en los relatos comentados ilustra una tendencia acentuada en la cuentística erótica de Jaramillo Levi la cual tiene que ver con la transformación de sus 
personajes en objetos fragmentados, separándolos, por tanto, de la idea de sujetos deseantes en tanto que éstos pudieran ocupar una posición fija en el desarrollo de la dialéctica de las pulsiones. De esta forma, lo que se explora es la relación entre el deseo y los objetos que fluyen y se interseccionan en movimiento constante para conformar, «máquinas deseantes», las cuales, en una producción semejante a la del bricolaje, permiten que el deseo y el objeto se conecten entre sí como máquinas que actúan en una producción conjunta al mismo tiempo que presentan un funcionamiento peculiar, el cual resulta en que éstas sólo trabajen al romperse continuadamente (8).

Es esta transformación de los personajes en objetos parciales que posibilita, por medio de una relación metonímica enfocada en un cuerpo desmembrado, que los que ellos compongan muchas veces una única entidad representada por miembros dispersos que rechazan en la escritura una composición orgánica. Es precisamente esta aglutinación lo que revela, en última instancia, la violencia potencial que habita el inconsciente, velada bajo la representación de la relación sexual. En este sentido, la amalgama entre lo síquico y lo social presente en una dirección de la cuentística erótica del escritor panameño plantea una cuestión de difícil resolución en lo que concierne a la teoría del deseo y su manifestación en la sexualidad, sugiriendo que la cuestión de cuerpos deseantes en su vertiente de máquinas repetitivas o de flujos no medulares no nace de una necesidad individual sino que más bien se sitúa en un punto fronterizo en el cual las fantasías sociales son absorbidas y reelaboradas por la siquis. Este intercambio entre las fuerzas sicológicas y las sociales en la conformación del deseo explica la existencia en la narrativa del autor de Un instante y otras eternidades de una expansión de la sexualidad que sobrepasa los límites del cuerpo y del individuo para reafirmarse como un campo saturado de intensidades en el cual el sujeto individual — si es que existe - fluctúa y se fragmenta formando, así, multiplicidades no taxonómicas ni traducibles sino más bien alteridades comprensibles sólo desde su captación artística. 